\section{Palliative splenic irradiation in primary and post PV/ET myelofibrosis: outcomes and toxicity of three radiation schedules}

\author{
Mario Federico, ${ }^{1,5,6}$ Guido Pagnucco, ${ }^{3}$ \\ Antonio Russo, ${ }^{5,6}$ Giovanni Cardinale, ${ }^{3}$ \\ Patrizia Guerrieri, ${ }^{2}$ Francesco Sciumè, ${ }^{2}$ \\ Catherine Symonds, ${ }^{6}$ Letizia Cito, ${ }^{6,7}$ \\ Sergio Siragusa, ${ }^{4}$ Nicola Gebbia, ${ }^{5}$ \\ Roberto Lagalla, ${ }^{1}$ Massimo Midiri, \\ Antonio Giordano, ${ }^{6}$ Paolo Montemaggi ${ }^{2}$ \\ 'U.O. Radioterapia, DiBiMeL, Università \\ degli Studi di Palermo, Italy \\ ${ }^{2}$ U.O. Radioterapia, ARNAS Civico, \\ Dipartimento Oncologico M. Ascoli, \\ Palermo, Italy \\ ${ }^{3}$ U.O. Ematologia, ARNAS Civico, \\ Dipartimento Oncologico M. Ascoli, \\ Palermo, Italy \\ ${ }^{4}$ U.O. Ematologia, Università degli Studi \\ di Palermo, Italy \\ ${ }^{5}$ U.O. Oncologia Medica, Dipartimento di \\ Chirurgia e Oncologia, Università degli \\ Studi di Palermo, Italy \\ 'Sbarro Health Research Organization, \\ Temple University, Philadelphia, USA \\ ${ }^{7}$ CROM, Centro Ricerche Oncologiche, \\ Mercogliano, Italy
}

\section{Abstract}

Splenectomy and splenic irradiation (SI) are the sole treatment modalities to control drug resistant splenomegaly in patients with myelofibrosis (MF). SI has been used in poor surgical candidates but optimal total dose and fractionation are unclear. We retrospectively reviewed $14 \mathrm{MF}$ patients with symptomatic splenomegaly. Patients received a median of 10 fractions in two weeks. Fraction size ranged from 0.2-1.4 Gy, and total dose varied from 210.8 Gy per RT course. Overall results indicate that $81.8 \%$ of radiation courses achieved a significant spleen reduction. Splenic pain relief and gastrointestinal symptoms reduction were obtained in $94 \%$ and $91 \%$ of courses, respectively. Severe cytopenias occurred in $13 \%$ of radiation courses. Furthermore patients were divided in three groups according to the radiation dose they received: 6 patients in the lowdose group (LDG) received a normalized dose of $1.67 \mathrm{~Gy} ; 4$ patients in the intermediate-dose group (IDG) received a normalized dose 4.37 $\mathrm{Gy}$; the remaining 4 patients in the high-dose group (HDG) received a normalized dose of 9.2 Gy. Subgroup analysis showed that if no differ- ences in terms of treatment efficacy were seen among dose groups, hematologic toxicity rates distributed differently. Severe cytopenias occurred in $50 \%$ of courses in the HDG, and in the $14.3 \%$ and in $0 \%$ of the IDG and LDG, respectively. Spleen reduction and pain relief lasted for a median of 5.5 months in all groups. Due to the efficacy and tolerability of the lowdose irradiation 4 patients from the LDG and IDG were retreated and received on the whole 12 RT courses. Multiple retreatments did not show decremental trends in terms of rates of response to radiation nor in terms of duration of clinical response. Moreover, retreatment courses did not cause an increased rate of adverse effects and none of the retreated patients experienced severe hematologic toxicities. The average time of clinical benefit in retreated patients was much longer (21 months, range 44-10) than patients who were not retreated (5.75 months, range 3-6).

\section{Introduction}

Primary myelofibrosis ${ }^{1}(\mathrm{PM})$ is a Philadelphia negative chronic myeloid disorder (CMD) currently classified with polycythemia vera (PV) and essential thrombocythemia (ET) as a chronic myeloproliferative disease ${ }^{2}$ (MPDs). PM is a rare disease mainly affecting older people ${ }^{3}$ with a median survival of 3.5-5 years. ${ }^{4}$ The pathogenetic mechanism is not clearly understood but probably relates to a clonal stem-cell disorder that leads to ineffective erythropoiesis, dysplastic megakaryocyte hyperplasia and an increased ratio of immature to total granulocytes. ${ }^{5}$ These findings are characteristically accompanied by reactive bone marrow (BM) fibrosis that develops and is mediated by megakaryocyte-derived fibrogenic cytokines. ${ }^{6}$

Collagen fibrosis, presumably along with many other factors, interferes with normal hematopoietic processes, ultimately leading to erythroid hypoplasia. ${ }^{7,8}$ Due to BM fibrosis, in MF patients as well as those with post ET/PV $\mathrm{MF}$, an extramedullary hematopoietic process starts in the spleen or in multiple organs as an attempt to override BM failure, often leading to the development of splenomegaly or hepatosplenomegaly. Moreover, splenomegaly exacerbates cytopenias through the sequestration and destruction of hematopoietic elements. ${ }^{9}$

Progressive high-grade splenomegaly occurs in the majority of MF patients. Unfortunately the standard current pharmacological therapeutic options, due to their short periods of response, fail to control organomegaly and organomegaly-associated symptoms (abdominal pain and early satiety, weight loss, portal hypertension and profound
Correspondence: Mario Federico,

Policlinico Universitario Paolo Giaccone

U.0. Radioterapia, DiBiMeL,

Sezione Scienze Radiologiche,

Via del Vespro 127, 90127 Palermo, Italy

E-mail: mfede@temple.edu

Key words: myelofibrosis, splenomegaly, palliation, radiotherapy, low-dose irradiation.

Acknowledgments: our grateful thanks go to Prof. Giovanni Barosi who kindly reviewed the manuscript.

Received for publication: 16 January 2009.

Revision received: 2 April 2009.

Accepted for publication: 17 April 2009

This work is licensed under a Creative Commons Attribution 3.0 License (by-nc 3.0)

(C) Copyright M. Federico et al., 2009

Licensee PAGEPress, Italy

Hematology Reviews 2009; 1:e7

doi:10.4081/hr.2009.e7

fatigue), which account for much of the patient's discomfort. Also even though a new generation of "target drugs" are currently under intense investigation with some encouraging results, splenomegaly control still remains a crucial step for patients' quality of life improvement.

To date, splenectomy or splenic irradiation (SI) are the sole treatment modalities to control drug resistant splenomegaly in $\mathrm{MF}$ patients. When technically achievable splenectomy is currently the preferred treatment modality for MF based upon good, long-lasting outcome in term of organomegaly-related symptom palliation. ${ }^{9,10}$ Unfortunately, it is consistently associated with a significant rate of mortality as well as intra- and peri-operative complications. ${ }^{9,10} \mathrm{SI}$, instead, has been generally preferred in patients not undergoing surgery due to a poor general status or decline and allows for a good but transitory splenomegaly palliation. In fact, the major shortcoming of radiation is that its palliative effect on splenomegaly generally does not last longer than six months.

There is a general agreement that emerges from the literature to use RT at dose levels lower than in other hematologic malignancies; however, few studies have taken a retrospective look at SI. ${ }^{11}$ The indication for SI is still controversial $^{12}$ and there is not a precise unequivocal definition of the optimal total dose and fractionation, mainly due to the limited number of patients included in existing studies and the wide range of radiation schedules adopted. Moreover, it is unclear if re-irradiation of MF patients is a safe strategy to extend the overall time of clinical benefit that a single SI course allows. Here we aim to 
assess outcomes and complication rates of splenic irradiation in three cohorts of patients treated with different "low-dose" irradiation schedules.

\section{Patients and Methods}

After approval from our institutional research review committee, we retrospectively reviewed data concerning 15 patients (10 male, 5 female, median age at diagnosis 61 years, median age at first irradiation 67 years), 11 with a histologically proven diagnosis of PM and 4 with a post ET-MF complaining of a highgrade symptomatic splenomegaly that were consecutively referred to our institution from 1997-2007 (Table 1). All patients had a drug resistant splenomegaly and lacked any further treatment options. Before being admitted to radiation, patients had previously been judged unfit for surgery due to their general status or had refused splenectomy. Fourteen out of 15 underwent splenic irradiation and one was excluded due to pre-existing advanced heart failure (patient 14). In the 14 irradiated patients the first course of radiation occurred at a median of 58 months from the diagnosis of MF. All 14 treated patients had a severe splenomegaly with splenic pain, abdominal discomfort, and weight loss; 11 patients (84\%) had in concurrence constitutional symptoms such as night sweats, low-grade fever and an initial state of cachexya. All except 3 required red blood cell transfusions ( $\geq 2$ units per month).

Patients were scored (at the time of their first irradiation) on the basis of Dupriez's prognostic parameters $^{13}$ (Hb levels $<10 \mathrm{~g} / \mathrm{dL}$ Land WBC $<4$ or $>30 \times 10^{\%} / \mathrm{L}$ ) in three categories: high- , intermediate- and low-risk. Four patients belonged to the high-risk, 4 to the lowrisk and 6 to the intermediate-risk groups, respectively. All patients had already undergone a cytoreductive pharmacological treatment: 8 received hydroxyurea as a single modality treatment, one received hydroxyurea plus Ara-C, 2 patients received hydroxyurea plus 6-mercaptopurine, one received hydroxyurea and melphalan, one received busulphan and 3 patients were given thalidomide in association with conventional cytoreductive treatments. Radiation treatment was delivered by a Siemens 15 MV Linac with multi leaf collimator; all patients had a CT scan simulation (slice thickness $10 \mathrm{~mm}$ ) in the supine position. The treatment planning system (Plato system $\mathrm{v}$ 2.6.3.) was used and no patient immobilization devices were adopted during the simulation and treatment.

Two portal arrangements were alternatively used to encompass the entire spleen volume: antero-posterior (AP-PA), opposed parallel or opposed tangential in the attempt to reduce the dose to the left kidney. If the left kidney was displaced posteriorly, a tangential arrangement was provided; if the kidney was displaced medially an antero-posterior approach was arranged. In the planned evaluation process between target coverage and kidney sparing we assigned priority to left kidney sparing in order to reduce the total dose to the organ in case of multiple courses of splenic irradiation

Since our institutional standards of radia- tion for MF have changed during the past ten years, patients received different total doses and dose per fraction. To compare the various RT treatments we used the Normalized Tumor Dose $^{14}\left(\mathrm{NTD}^{10}\right)$, defined as the total dose delivered in 2 Gy fractions that corresponds to a particular biologically effective dose level and is calculated according to the formula:

$$
N T D_{10}=n d\left(\frac{1+\frac{d}{\alpha / \beta}}{1+\frac{2}{\alpha / \beta}}\right)
$$

where $\mathrm{n}$ is the number of RT fractions and $\mathrm{d}$ the fraction size in Gy. The $\alpha / \beta$ value of the Linear Quadratic Model ${ }^{15}$ was empirically fixed to 10 as for early responding tissues. By standardizing the delivered dose of all 22 administered treatments into a 2 Gy isoeffective treatment, we were able to make a correct radiobiological comparison among different RT schedules. On the basis of the NTD values, patients were divided into three different groups but it should be underlined that RT schedules were not chosen on the basis of patients' clinical parameters but rather were dependent on the progressive modification of our institutional treatment philosophy.

The initial patients, who had received a total dose of 10 Gy with a dose per fraction in the order of $1 \mathrm{~Gy}$, were designated as our highdose group (HDG). Patients who had received our current standard of treatment $(0.2$ Gy fraction up to a total dose of 2 Gy in 10 fractions)

Table 1. Patients' characteristics at the time of first irradiation.

\begin{tabular}{|c|c|c|c|c|c|c|c|c|}
\hline Patient N. & $\begin{array}{l}\text { Age at } \\
\text { irradiation } \\
\text { and sex }\end{array}$ & $\begin{array}{l}\text { Interval } \\
\text { diagnosis } \\
\text { irradiation } \\
\text { intent to treat) }\end{array}$ & $\begin{array}{l}\text { Dupriez } \\
\text { score }\end{array}$ & $\begin{array}{l}\text { Previous } \\
\text { treatments }\end{array}$ & $\begin{array}{l}\text { Symptoms } \\
\text { at time } \\
\text { of radiation }\end{array}$ & $\begin{array}{c}\text { RBC } \\
\text { transfusion } \\
\text { U/month }\end{array}$ & $\begin{array}{c}\text { Pre- } \\
\text { irradiation WBC } \\
\times 10^{9} / \mathrm{L}\end{array}$ & $\begin{array}{c}\text { Pre- } \\
\text { irradiation PLT } \\
\times 10^{9} / \mathrm{L}\end{array}$ \\
\hline $1^{*}$ & $53 \mathrm{~F}$ & $14 \mathrm{y}$ & HR & HU & $\mathrm{S}, \mathrm{P}$ & $2 \mathrm{U}$ & 39.9 & 232 \\
\hline $2^{*}$ & $65 \mathrm{~F}$ & $16 \mathrm{y}$. & IR & $\mathrm{HU}$ & S, P, CS & $4 \mathrm{U}$ & 6.48 & 381 \\
\hline 3 & $62 \mathrm{~F}$ & $3 \mathrm{y}$ & LR & HU; MPH & $\mathrm{S}, \mathrm{P}$ & $2 \mathrm{U}$ & 9.55 & 21 \\
\hline $4^{*}$ & $75 \mathrm{~F}$ & $8 \mathrm{y}$. & LR & HU & $\mathrm{S}, \mathrm{P}, \mathrm{CS}$ & $2 \mathrm{U}$ & 8.36 & 44 \\
\hline 5 & $67 \mathrm{M}$ & $4 \mathrm{y}$. & IR & $\mathrm{HU}$ & $\mathrm{S}, \mathrm{P}, \mathrm{CS}$ & $2 \mathrm{U}$ & 5.7 & 210 \\
\hline 6 & $67 \mathrm{M}$ & $8 \mathrm{y}$. & IR & HU; Ara-C & S, P & NT & 38.1 & 190 \\
\hline 7 & $77 \mathrm{M}$ & $8 \mathrm{y}$ & LR & HU; 6-MP & $\mathrm{S}, \mathrm{P}, \mathrm{CS}$ & $2 \mathrm{U}$ & 10.3 & 423 \\
\hline 8 & $87 \mathrm{M}$ & $1 \mathrm{y}$. & HR & B; Th & $\mathrm{S}, \mathrm{P}, \mathrm{CS}$ & $2 \mathrm{U}$ & 2.63 & 119 \\
\hline 9 & $46 \mathrm{M}$ & $4 \mathrm{y}$. & IR & $\mathrm{HU}$ & $\mathrm{S}, \mathrm{P}, \mathrm{CS}$ & NT & 29.6 & 307 \\
\hline 10 & $67 \mathrm{M}$ & $1 \mathrm{y}$. & IR & $\mathrm{HU}$ & $\mathrm{S}, \mathrm{P}, \mathrm{CS}$ & $2 \mathrm{U}$ & 4.9 & 121 \\
\hline 11 & $70 \mathrm{M}$ & $2 \mathrm{y}$. & HR & $\mathrm{HU}$ & $\mathrm{S}, \mathrm{P}, \mathrm{CS}$ & $2 \mathrm{U}$ & 89 & 143 \\
\hline 12 & $58 \mathrm{M}$ & $7 \mathrm{y}$ & LR & HU; Th & S, P, night sweats & NT & 10.89 & 329 \\
\hline $13^{*}$ & $65 \mathrm{M}$ & $2 \mathrm{y}$. & IR & HU; 6-MP; Th & $\mathrm{S}, \mathrm{P}, \mathrm{CS}$ & $2 \mathrm{U}$ & 8 & 673 \\
\hline 14 & $76 \mathrm{M}$ & $4 \mathrm{y}$. & HR & $\mathrm{HU}$ & $\mathrm{S}, \mathrm{P}, \mathrm{CS}$ & $4 \mathrm{U}$ & 1.04 & 67 \\
\hline 15 & $55 \mathrm{~F}$ & 4 y. & HR & HU; Th & $\mathrm{S}, \mathrm{P}, \mathrm{CS}$ & $2 \mathrm{U}$ & 42.51 & 143 \\
\hline
\end{tabular}

S: Splenomegaly; P: splenic pain; CS: constitutional symptom; HU: Hydroxyurea; Th: Thalidomide; 6-MP: 6-Mercaptopurine; ARA-C: Arabinosylcytosine; MPH: Melphalan; B: Busulphan; HR: High-risk; IR: Intermediate-risk; LR: Low-risk; NT:Not transfused. ${ }^{*}$ Post ET - MF. 
were designated as our low-dose group (LDG). Whereas the intermediate-dose group (IDG) reflected the transition or better our "dose finding effort" toward lower doses with the aim to reduce treatment related toxicities (Supplementary Tables). The IDG encompasses patients who had received a wide range of treatment with radiobiological characteristics, which, in some cases, may partially overlap with the LDG. However, we decided to aggregate our patients in this way in order to obtain homogeneity in the low- and in the high-dose groups.

Patients in which three or more of the following criteria were present were considered responsive to treatment: subjective absence of MF-related gastrointestinal symptoms (bulky effect), absence of splenic pain, consistent reduction of the spleen volume (not less than $50 \%$ of the initial size) assessed by clinical examination (according to the formula: spleen volume $=4 / 3 \pi 1^{\circ}$ diameter $^{\circ} 2^{\circ}$ diameter $^{\circ} 3^{\circ}$ diameter) and, finally, reduction of the RBC transfusion units required per month.

To evaluate toxicity and response to treatment, patients had undergone clinical examination and blood cell count twice a week during the period of irradiation and for the following two weeks. If no toxicity occurred, blood tests were scheduled weekly for the following month. The evaluation of the spleen reduction was carried out 20 days after patients had completed radiation.

Treatment related toxicity was limited to myelosuppression and was measured on the basis of RTOG acute toxicity scoring criteria. An RT course after which a post-radiation grade 4 (WBC count $\leq 1 \times 10^{\circ} / \mathrm{L}$ and/or PLTs count $\leq 20 \times 10^{9} / \mathrm{L}$ ) acute cytopenia had developed was considered too toxic. RBC count was excluded from toxicity scoring because almost all patients were already heavily transfused long before receiving RT. Due to the small size of the study cohort and the lack of homogeneity in patients' characteristic due to the accrual criteria, we did not perform any statistical data analysis, as it would not be statistically representative or pertinent.

\section{Results}

Total delivered dose per RT course ranged from 2 to $10.8 \mathrm{~Gy}$, the dose per fraction varied from 0.2-1.4 Gy. RT courses were generally administered over a two week period (median number of fraction per RT course was 10), patients received RT five days per week continuously; 4 patients had multiple courses of RT, and one patient received 4 courses. In the first group (low-dose group, LDG), 6 patients received a median NTD of 1.67 Gy ( 0.6 standard deviation). In the second (intermediatedose group, IDG), 4 patients had a median NTD of 4.37 Gy (1.89 standard deviation). The third group (high-dose group, HDG) contained 4 patients who received a normalized median dose of $9.2 \mathrm{~Gy}$ (0.46 standard deviation).

According to the above-defined criteria, 12 patients were considered responsive. Overall response rates after all 22 RT treatments indicate that $81.8 \%$ of courses achieved a significant spleen size reduction; however, better results were achieved on splenic pain relief (94.45\% of RT courses) and reduction of gastrointestinal symptoms ( $91 \%$ of courses). No significant difference in terms of spleen size reduction and splenic pain relief emerged after subgroup analysis. Patients in the LDG had spleen size reduction and splenic pain relief in $91 \%$ and $100 \%$ of courses, respectively, while in the IDG and in the HDG, $76.5 \%$ and $75 \%$ of courses obtained a spleen size reduction. Pain relief was achieved in $86 \%$ and $100 \%$, respectively (Table 2).
After completing radiation all responsive patients had an improvement in their body weight while SI was less effective in reducing patients' transfusion requirements. In only $35.3 \%$ (6/17) of courses there was a slight improvement of anemic state, but this was transient and shorter than spleen size reduction and pain relief.

Within the entire study population, grade 4 RTOG life-threatening cytopenias occurred in $21.5 \%$ of patients (3/14) or $13.6 \%$ of RT courses. In all cases it developed in the first week after completing radiation and required hospitalization. Interestingly, RT complications distributed differently among groups. In the LDG, no grade 4 RTOG adverse effects occurred. Patients in the IDG experienced $14.3 \%$ of RT courses followed by severe cytopenias (1/ 7 courses), while in the HDG, $50 \%$ of RT treatments were too toxic (Supplementary Figure 1). Both non-responding patients (patients 9 and 8) experienced severe acute complications. One (patient 8) appeared to have been rescued from cytopenia but three months later developed a leukemic transformation that led to death. The second patient (patient 9), complained of a massive splenomegaly, did not respond to SI and underwent splenectomy 12 months after RT. One month after splenectomy the patient died as a result of sepsis.

The median time of symptom relief after a single RT course was 5.5 months and no differences were found among dosage groups. According to the patients' general conditions, the cumulative RT dose delivered and the rate of spleen shrinkage in response to previous irradiation, retreatment after splenic relapse was considered in 4 patients. The 4 retreated patients received on the whole 12 RT courses and one patient received 4 courses without any acute toxicity. Two of the retreated patients belonged to the LDG and the remaining 2 to the IDG. However, it is important to note that

Table 2. Splenic irradiation results (by NTD group).

\begin{tabular}{|c|c|c|c|c|c|c|c|c|c|c|c|}
\hline & $\mathrm{Nu}$ & Jatients & Median & Number & Median Dose & & & & Respo & onse & \\
\hline & PM & $\begin{array}{l}\text { Post } \\
\text { ET MF }\end{array}$ & $\begin{array}{c}\text { dose } \\
\text { delivered }\end{array}$ & of courses & per fraction & m & sd & $\begin{array}{l}\% \text { of courses } \\
\text { with reduction } \\
\text { in spleen size }\end{array}$ & $\begin{array}{l}\% \text { of courses } \\
\text { with pain relief }\end{array}$ & $\begin{array}{c}\text { Median duration } \\
\text { of response } \\
\text { (in months) }\end{array}$ & $\begin{array}{l}\text { Hematologic } \\
\text { toxicity } \\
\text { Grade } 4 \\
\text { RTOG }\end{array}$ \\
\hline LDR & 3 & 3 & $\begin{array}{c}200 \text { cGy } \\
\text { (2-4 Gy range) }\end{array}$ & 11 & $20 \mathrm{cGy}$ & $1.67 \mathrm{~Gy}$ & 0.60 & $91 \%$ & $100 \%$ & 6 months & $\begin{array}{c}0 \% \\
\text { (range 3-12) }\end{array}$ \\
\hline HDR & 4 & 0 & $\begin{array}{c}1000 \text { cGy } \\
\text { range } \\
(980-1080 \mathrm{cGy})\end{array}$ & 4 & 110 cGy & $9.20 \mathrm{~Gy}$ & 0.46 & $75 \%$ & $100 \%$ & $\begin{array}{l}4 \text { months } \\
\text { (range 6-0) }\end{array}$ & $\begin{array}{c}50 \% \\
(2 / 4)\end{array}$ \\
\hline IDR & 3 & 1 & $\begin{array}{l}500 \text { cGy } \\
\text { Range }\end{array}$ & 7 & $50 \mathrm{cGy}$ & $4.37 \mathrm{~Gy}$ & 1.89 & $76.5 \%$ & $86 \%$ & $\begin{array}{l}5 \text { months } \\
\text { (range 6-0) }\end{array}$ & $\begin{array}{l}14.3 \% \\
(1 / 7)\end{array}$ \\
\hline
\end{tabular}

Low-dose group ( $L D G)$; high-dose group (HDG); intermediate-dose group (IDG); median (m) standard deviation (sd). 
of the patients retreated from the IDG, one received treatments of 0.3 up to 3 Gy in 10 fractions total, which could be considered radiobiologically partially overlapping with the treatment dosages of the LDG.

In comparison to the first irradiation, multiple retreatments did not show decremental trends in terms of rates of response to radiation nor in terms of duration of clinical response. Even in the case of one patient, who received 4 RT courses, there was no change in the duration of symptoms' palliation. Moreover, after retreatment courses we did not observe an increased rate of adverse effects and none of the retreated patients experienced severe hematologic toxicities. The average time of clinical benefit (Supplementary Figure 2 ) in retreated patients was very much longer (21 months, range 44-10) than patients who were not retreated (5.75 months, range 3-6).

\section{Discussion}

Splenomegaly rapidly occurs in all MF patients and is one of the causes of major discomfort. Curative treatments are to-date still limited in MF. Allogenic bone marrow transplantation (allo-BMT) has shown promising results in younger patients but its role in elderly patients is controversial. In particular, several studies suggest that in individuals older than 45 the treatment's risk-related mortality outweighs the benefits. ${ }^{16}$ On the contrary, other studies more recently explored the use of allo-BMT also in patients older than 60 with some interesting results. ${ }^{17,18}$ Currently, BMT in the elderly is still a matter of debate since the number of patients accrued in clinical trials is limited and the follow-up time short. Since MF remains a disease of the elderly, standard and palliative treatments to manage cytopenias and massive organomegaly still retain a relevant role in a consistent proportion of patients.

Splenomegaly can be effectively controlled by conventional cytotoxic chemotherapy ${ }^{19}$ until patients become drug resistant. More recently atiangiogenic drugs and target drugs are expected to offer a new chance of treatment for all patients. In particular a new class of molecules designed to inhibit Jak have been tested in different phase II trials with positive results. ${ }^{20} \mathrm{Jak}$ inhibitors have shown a significant activity on splenomegaly but there is no reason to think that, along with their use, also resistant patients will be selected.

After massive splenomegaly is established, splenectomy is considered the principle palliative measure because it offers a lengthy relief of symptoms. Unfortunately splenectomy is weighted by significant morbidity and mortality rates. The two largest single institution series from Barosi ${ }^{10}$ and Tefferi ${ }^{9}$ reported a mortality rate of $8.4 \%$ and $9 \%$, respectively, with the latter increasing to $26 \%$ when the three-month post-splenectomy period was considered, and a morbidity rate of $39.3 \%$ and $31 \%$, respectively. After splenectomy, up to $25 \%$ of patients may experience accelerated hepatomegaly and extreme thrombocytosis. ${ }^{21}$ Moreover, splenectomy has also been correlated to a significantly higher incidence of blast transformation.

A large Italian study demonstrated a crude transformation rate in splenectomized patients of $26.4 \%$ in comparison to $11.9 \%$ in non-splenectomized patients with the cumulative actuarial transformation rate of $55 \%$ in splenectomized vs. $27 \%$ in non-splenectomized patients at 12 years after diagnosis. The overall relative risk of blast transformation was therefore 2.61 times higher among splenectomized patients. ${ }^{22}$ In conclusion, despite the impact on symptoms, no overall survival benefit has been demonstrated after splenectomy ${ }^{9,23}$ on the contrary, this procedure is associated with a substantial risk of operative mortality, early and late morbidity and is contraindicated in patients with thrombocytosis. Furthermore, splenectomy has been shown to be a predictor of treatment failure in case of allo-BMT. ${ }^{16}$ Alternative treatments to manage splenomegaly, with lower morbidity and mortality rates, would offer a significant improvement in the clinical management of MF patients.

Radiotherapy has been used in selected situations to control extramedullary hematopoiesis, as in spinal localizations, ${ }^{24}$ in pulmonary hypertension ${ }^{25}$ or in symptomatic hepatomegaly $^{26}$ with promising results. However, its role in splenic palliation remains controversial because of the lack of robust data (Table 3). It has been shown that splenic irradiation can be very effective in reducing spleen size and splenic pain with response rates comparable to splenectomy. ${ }^{33}$ The major shortcoming of radiotherapy is the reliance on its transient effect that normally does not exceed six months.

As an alternative to splenectomy, SI has been considered in poor surgical candidates or in patients who declined surgery. In these patients, that generally are in a worse condition compared to those that undergo surgery, palliative splenic irradiation has shown mortality rates that are comparable to splenectomy. ${ }^{27}$ On the other hand, a high rate of severe life-threatening cytopenias has been reported in patients that underwent splenic irradiation, ranging from $32 \%$ (16/50 courses) of the Mayo Clinic series ${ }^{27}$ where lower doses of RT were used (median dose per course $2.775 \mathrm{~Gy}$ ) to $35 \%$ (6/17 courses) of a French series ${ }^{31}$ where a more aggressive treatment was delivered (median dose per course $9.8 \mathrm{~Gy}$ ).

Although a general trend in favor of low doses is emerging in the literature, the wide variability of total radiation doses, the different number of fractions, as well as the different schedule of irradiation reported, makes it difficult to define a standard of treatment. ${ }^{33}$

In order to be able to make dose-effect comparisons, the major drawback of some of the published series is that the total dose and the fractionation scheme seem not to be decided up-front from the treatment but modified during the irradiation on the basis of the single patient response with a consequent high variability in the total dose, fractionation and overall treatment time. Some authors ${ }^{31}$ used the common 5 daily fractions per week schedule but increased the fraction size during the radiation course (from 0.4-0.5 Gy/fraction in the first week of treatment, up to $0.8-1 \mathrm{~Gy} /$ fraction during the following weeks) until the palliative effect or toxicity is reached. Other authors ${ }^{30}$ give radiation 2-3 times per week with an altered time factor. Both such approaches can be empirically effective but generate data that are difficult to compare with the common radiobiology algorithms that are based on larger daily fraction sizes (around $2 \mathrm{~Gy}$ ) and with a time of inter-course sub-lethal DNA damage repair of 24 hours between fractions. Given that it is hard to make radiobiological comparisons among some published series, it is clear that, still now, the most critical issue regarding a rational use of RT is the definition of an optimal total dose and fractionation.

The leading idea of our approach to SI has been to adopt a relative long fractionation schedule of 10 fractions in two weeks independent of the total dose delivered with the intent to generate comparable results, also in case of treatments differing in total dose and dose per fraction. This approach should also minimize the incidence rate of post-attinic severe cytopenias and favor a rapid recovery of early blood precursors from RT. In fact, since a strong dose-sparing effect of fractionation on bone marrow precursors ${ }^{34,35}$ has been proven, we believed that it would be meaningful to also apply this concept to extramedullary hematopoiesis sites. Therefore, we decided to utilize a long RT schedule (median 10 fractions) even when it could appear unjustified to do so due to the minimal total dose delivered.

Regarding the total dose, at the beginning of our experience, we adopted an aggressive RT regimen (1 Gy per fraction up to a total dose of $10 \mathrm{~Gy}$ ) but we observed a high incidence of severe side effects. This raised the concern that the same stem clonal disorder that underlies MF could make hematopoietic precursors more sensitive to radiation. In order to reduce the incidence of acute cytopenias we progressively reduced total RT doses until we established our actual standard of care (0.2 Gy per fraction up to 2 Gy total dose).

Our findings show that extremely low-dose 
Table 3. Synoptic table of published data on palliative SI in myelofibrosis.

\begin{tabular}{|c|c|c|c|c|c|c|c|c|c|c|}
\hline \multirow[t]{2}{*}{ Author } & \multicolumn{2}{|c|}{ Number of patients } & \multirow{2}{*}{$\begin{array}{l}\text { Median } \\
\text { dose } \\
\text { delivered }\end{array}$} & \multirow{2}{*}{$\begin{array}{c}\# \\
\text { of RT } \\
\text { courses }\end{array}$} & \multirow{2}{*}{$\begin{array}{c}\text { Median } \\
\text { dose } \\
\text { per } \\
\text { fraction }\end{array}$} & \multicolumn{2}{|c|}{ Estimated NTD10 } & \multicolumn{3}{|c|}{ Response } \\
\hline & MF & $\begin{array}{l}\text { Post } \\
\text { PV/ET }\end{array}$ & & & & Median & $\begin{array}{c}\text { Dev } \\
\text { standard }\end{array}$ & $\begin{array}{l}\% \text { of courses } \\
\text { with reduction } \\
\text { in spleen size }\end{array}$ & $\begin{array}{c}\% \text { of courses } \\
\text { with pain } \\
\text { relief }\end{array}$ & $\begin{array}{c}\text { Median duration } \\
\text { of response } \\
\text { (In months) }\end{array}$ \\
\hline Elliot $^{27}$ & 18 & 5 & $\begin{array}{l}277.5 \mathrm{cGy} \\
\text { range } \\
(30-1365 \mathrm{~Gy})\end{array}$ & 50 & $50 \mathrm{cGy}$ & 3,162 Gy & 2,784 & $94 \%$ & $96 \%$ & $\begin{array}{c}6 \\
\text { range } \\
(1-41)\end{array}$ \\
\hline Greenberger $^{28}$ & 13 & 1 & $\begin{array}{l}650 \text { cGy range } \\
\text { (40-1728 cGy) }\end{array}$ & 21 & $57.14 \mathrm{cGy}$ & 5,807 Gy & 3,204 & $95 \%$ & $100 \%$ & $\begin{array}{l}\text { NV } \\
\text { range } \\
(1-73)\end{array}$ \\
\hline Parmentier $^{29}$ & 5 & 4 & $\begin{array}{l}690 \text { cGy range } \\
\text { (180-2900 cGy) }\end{array}$ & 12 & $\begin{array}{l}25 \mathrm{cGy} \\
\text { range } \\
(12,5-75)\end{array}$ & 5,845 Gy & 6,451 & $92 \%$ & NA & NA \\
\hline Wagner $^{30}$ & 6 & $\begin{array}{l}0 \\
\text { From } \\
\text { fra }\end{array}$ & $\begin{array}{c}\text { NA } \\
200-450 \text { cGy in } 2 \\
\text { tion } 3 \text { times per }\end{array}$ & $\begin{array}{l}\text { NA } \\
\text {-50 cGy } \\
\text { week }\end{array}$ & NA & NA & NA & $80 \%$ & $63 \%$ & $\mathrm{NA}$ \\
\hline Bouabdallah $^{31}$ & 15 & 0 & $\begin{array}{c}980 \mathrm{cGy} \\
(60-3050 \mathrm{cGy})\end{array}$ & 17 & $\begin{array}{l}\text { Daily fr. } \\
40-100 \text { cGy } \\
\text { median } \\
\text { duration } \\
22 \text { days }\end{array}$ & $\mathrm{NA}$ & NA & $81 \%$ & $90 \%$ & $\begin{array}{l}\text { Spleen size reduction } \\
6 \text { months range } \\
\text { (1-24 months) } \\
\text { Splenic pain } 7 \text { months } \\
\text { Range (1-19 months) }\end{array}$ \\
\hline Mc Farland ${ }^{32}$ & 4 & 2 & $\begin{array}{l}\text { range } \\
300-600 \text { cGy }\end{array}$ & 13 & $\begin{array}{l}\text { Irradiation } \\
\text { twice wk: } \\
\text { 1stw50cGy } \\
\text { 2ndw75cGy } \\
\text { 3rdw100cGy }\end{array}$ & NA & $\mathrm{NA}$ & $92 \%$ & NA & $\begin{array}{c}\text { MF: } 1-16 \text { months } \\
\text { Post PV/MF: } 2-12 \text { months }\end{array}$ \\
\hline $\begin{array}{l}\text { Present study } \\
\text { LDG }\end{array}$ & 3 & 3 & $\begin{array}{c}200 \text { cGy } \\
\text { range } \\
(200-400 \text { cGy })\end{array}$ & 11 & 20 cGy & $1.67 \mathrm{~Gy}$ & 0.603 & $91 \%$ & $100 \%$ & $\begin{array}{l}6 \text { months } \\
\text { (range 3-12) }\end{array}$ \\
\hline $\mathrm{HDG}$ & 4 & 0 & $\begin{array}{c}1000 \text { cGy } \\
\text { range } \\
(980-1080 \text { cGy) }\end{array}$ & 4 & 110 cGy & $9.205 \mathrm{~Gy}$ & 0.465 & $75 \%$ & $100 \%$ & $\begin{array}{l}4 \text { months } \\
\text { (range 6-0) }\end{array}$ \\
\hline IDG & 3 & 1 & $\begin{array}{c}500 \text { cGy } \\
\text { range } \\
(300-800 \text { cGy })\end{array}$ & 7 & 50 cGy & 4.375 Gy & 1.892 & $76,5 \%$ & $86 \%$ & $\begin{array}{l}5 \text { months } \\
\text { (range 6-0) }\end{array}$ \\
\hline
\end{tabular}

NA: not assessable.

treatments are isoeffective as compared to higher dose regimens in effectively reducing splenomegaly. Unfortunately, we cannot explain the functionality of low-dose treatment regimens in being so effective as compared to high-dose treatments; however, these findings are in concordance with the hypothesis of lowdose hypersensitivity. ${ }^{36}$ The suggestive issue of radiobiology has been intensely investigated in vitro ${ }^{37}$ and postulates a hypersensivity state of cells when irradiated at low doses $(<0.4-0.5$ Gy). Recently, there have been several indirect confirmations of this theory in clinical studies, linking low-dose hypersensivity to tumor regression ${ }^{38}$ as well as to the occurrence of adverse effects, ${ }^{39}$ at dose levels under the threshold generally accepted for toxicity or tumor control.

Since in our series, as well as in others reported, ${ }^{27-29,31}$ there is an inherent discrepancy due to variability in total dose delivered, fraction number, and fraction size, to be able to correctly compare different treatments we used the NTD formula, a radiobiological tool commonly used in the clinic to evaluate the biological effectiveness of modified RT fractionations. The overall NTD 10 of all 22 RT courses in our series is $2.59 \mathrm{~Gy}$, a value comparable with the median NTD ${ }^{10}$ estimated from the Mayo series (3.16 Gy). Interestingly our patients seem to have a lower overall incidence rate of grade 4 RTOG (13.6\% of courses $v s$. $32 \%)$. This discrepancy is somehow difficult to be explained since there are just slight differences in the normalized radiation dose that patients of the two groups received. Even a slighter difference in terms of patient characteristics can be found between the Mayo Clinic series and ours (median age at the time of the first irradiation 65 vs. 67 years; time intercur- ring between diagnosis and irradiation $44 \mathrm{vs}$. 58 months, respectively). A possible explanation could be that in the definition of toxicity criteria, differing from the Mayo report, we did not consider hemoglobin levels since the majority of our patients were transfused from a long time before receiving radiotherapy. Another possible explanation could rely on the medical treatment that patients received before undergoing radiation: in fact, it is interesting to note that the only 2 patients in both series that received melphalan as medical treatment before radiation later experienced severe post-attinic cytopenias.

To compare outcomes after different radiation doses we stratified our patients into three groups according to the NTD ${ }^{10}$ value they received. We found that, if no differences in terms of spleen shrinkage or pain relief emerged among patients who underwent dif- 
ferent RT regimens, daily fractions of 0.2 Gy up to 2 Gy is significantly the safer fractionation scheme since it is not associated to grade 4 hematologic toxicities. In our patients, independently from the dose, radiotherapy was very effective in reducing massive splenomegaly, but did not resolve completely the spleen enlargement (Supplementary Tables). It is possible to argue that, since we found a safe RT schedule, it would be meaningful to prolong the radiation treatment until a complete splenomegaly remission. On the contrary, we decided to maintain a conservative approach and to stop the treatment once the planned final dose was achieved. Two main considerations led to our decision: first of all the fact that the palliative effect of radiotherapy seems to last no longer than six months independently from the dose delivered. We were concerned that reducing the spleen size until normalization could result in a small increase of the time free from symptoms at the cost of a probably higher incidence of severe cytopenias. Secondly, since the aim of our treatment was strictly palliative, we considered it meaningful, once symptom relief was achieved, to stop the treatment with the intent to minimize the patient's absorbed dose per course of RT in order to potentially be able to repeat the treatment in the future.

In fact, because of the low incidence of mild adverse effects in the LDG (and in the lower dose burden of the IDG) we were able to repeat the irradiation several times thus prolonging the clinical benefit much more than expected.

Four patients safely underwent 12 RT courses with no occurrence of grade 4 RTOG hematologic toxicity. All the retreated patients belong to the low-or intermediate-risk group. In these patients the intensity and the persistence of splenic response to irradiation did not change under multiple retreatment courses. However, retreatment increased the average time of symptoms relief four fold longer than in un-retreated patients (21 months vs. 5.75). It could be argued that a possible bias in our work is that all the post ET-MF patients were allocated in the LDG or in the inferior burden of other IDG but this fact could not modify the consistency of the presented data; especially because just one patient with post ET-MF has been retreated so far. We propose that the results regarding the average time of clinical benefit in retreated patients can be considered substantially valid for primary MF patients. Furthermore, it deserves to be mentioned that, in comparison to MF patients, a shorter interval free from symptoms has been reported after $\mathrm{SI}^{32}$ in post-ET MF patients.

With all the limitations inherent in the small number of patients examined, we found that in our series Dupriez's score (calculated at the time of patient's referral to the radio- therapy department) is not predictive of response to palliative radiotherapy or occurrence of toxicity. We conclude that our actual standard of 2 Gy delivered in 10 fractions over two weeks has a NTD of $1.67 \mathrm{~Gy}$, a value twoto three-fold lower than other published series. This schedule of treatment has been shown to be extremely well tolerated and to date in our experience is not associated with severe hematologic toxicities. Such optimal treatment compliance encouraged repeating irradiation in responsive patients and this favored a drastic increase in the average time of clinical benefit.

\section{References}

1. Mesa RA, Verstovsek S, Cervantes F, Barosi G et al. Primary Myelofibrosis (PMF) post polycythemia vera myelofibrosis (post-PV MF), post essential thrombocythemia myelofibrosis (post-ET MF), blast phase PMF (PMF-BP): Consensus on terminology by the international working group for myelofibrosis research and treatment (IWG-MRT). Leuk Res 2007;737-40.

2. Tefferi A. Classification, diagnosis and management of myeloproliferative disorders in the JAK2V617F Era. Hematology Am Soc Hematol Educ Program 2006;2405.

3. Visani G, Finelli C, Castelli U, et al. Myelofibrosis with myeloid metaplasia: clinical and haematological parameters predicting survival in a series of 133 patients. Br J Haematol 1990;75:4-9.

4. Guardiola P et al. Allogenic stem cell trasplantation for agnogenic myeloid metaplasia: a European Group for Blood and Marrow Trasplantation, Società Francaise de Greffe de Moelle, Gruppo Italiano per il trapianto di Midollo Osseo e Fred Hutchinson Cancer Research Center Collaborative Study. Blood 1999;93:2831-8.

5. Tefferi A. Myelofibrosis with myeloid metaplasia. N Engl J Med 2000;342:125565.

6. Reilly JT. Idiopathic myelofibrosis: pathogenesis, natural history and management. Blood Rev 1997;11:233.

7. Thiele HM, Werden J, et al. Prognostic factors in idiopathic (primary) osteomyelofibrosis. Cancer 1997;80:708.

8. Thiele J, Windecker R, Kvasnicka HM et al. Erythropoiesis in primary (idiopathic. osteomyelofibrosis: quantification, PCNAreativity and prognostic impact. Am J Hematol 1994;46:36.

9. Tefferi A., Mesa RA, Nagorney DM. Splenectomy in myelofibrosis with myeloid metaplasia: a single institution experience with 223 patients. Blood 2000; 95:2226-33.

10. Barosi G, Ambrosetti A, Buratti A, et al. Splenectomy for patients with myelofibrosis with myeloid metaplasia: retreatment variables and outcome predictions. Leukemia 1993;7:200-6.

11. Mesa RA, Tefferi A. Surgical and radiotherapeutic approaches for myelofibrosis with myeloid metaplasia. Semin Oncol 2005;32: 403-13.

12. Coughlin C, Papac R, Roberts K. Leukemia. In: Perez C, Brady L. Halperin EC editors. Principles and practice of radiation oncology 4th edition 2004. Lippincott Williams \& Wilkins Philadelphia pp. 21423 .

13. Dupriez B, Morel P, Demory JL et al. Prognostic factors in agnogenic myeloid metaplasia. A report on 195 cases with a new scoring system. Blood 1996;88:1013-8.

14. Fowler JF, Tomè WA, Fenwick JD et al. A challenge to traditional radiation oncology. Int J Radiat Oncol Biol Phys 2004;60:1241-56.

15. Fowler JF. The Linear Quadratic formula and progress in fractionated radiotherapy. Br J Radiol 1989;62:679-94.

16. Cervantes F. Myelofibrosis: biology and treatment options. Eur J Haematol 2007; 79:13-7.

17. Samuelson SJ, Sandmaier BM, Heslop HE et al. Allogenic hematopoietic cell transplants in patients with Myelofibrosis age 60 and older. Blood 2008;112:Abstr. 2798.

18. Popat UR, Rondon G, Alousi AM et al. Myelofibrosis and reduced intensity allogenic hematopoietic stem cell transplantation (RISCT). Blood 2007;110:Abstr. 3062.

19. Mesa R. How I treat symptomatic splenomegaly in patients with myelofibrosis. Blood 2009. Epub ahead of print.

20. Verstovsek S, Kantarjian HM, Pardanani A et al. A phase I/II study of INCB018424, an oral, selective JAK inhibitor, in patients with primary myelofibrosis (PMF) and post polycythemia vera/essential thrombocythemia myelofibrosis (Post PV/ET MF). JC0 2008;26 Abstr. 7004.

21. Mesa RA, Nagorney DS, Schwager S. et al. Palliative goals, patient selection, and perioperative platelet management: Outcomes and lessons from 3 decades of splenectomy for myelofibrosis with myeloid metaplasia at the Mayo Clinic Cancer 2006;107:361-70.

22. Barosi G, Ambrosetti A, Centra A et al. Splenectomy and risk of blast transformation in myelofibrosis with myeloid metaplasia. Blood 1998;91:3630-6.

23. Bembassat J, Gilon D, Penchas S. The choice between splenectomy and medical treatment in patients with advanced agnogenic myeloid metaplasia. Am J Hematol 
1990;33:128-35.

24. Koch CA, Li CY, Mesa RA et al. Non hepatosplenic extramedullary hematopoiesis: associated disease, pathology, clinical course and treatment. Mayo Clin Proc 2003;78:1223-33.

25. Steensma DP et al. Low dose single fraction whole lung radiotherapy for pulmonary hypertension associated with myelofibrosis with myeloid metaplasia. $\mathrm{Br}$ J Haematol 2002;118:813-6.

26. Tefferi A et al. Radiation therapy for symptomatic hepatomegaly in myelofibrosis with myeloid metaplasia. Eur J Haematol 2001;66:37-42.

27. Elliott MA, Chen MG, Silverstein MN et al. Splenic irradiation for symptomatic splenomegaly associated with myelofibrosis with myeloid metaplasia. $\mathrm{Br} \mathrm{J}$ Haematol 1998;103:505-11.

28. Greenberger J, Chaffey J, Rosenthal D et al. Irradiation for control of hypersplenism and painful splenomegaly in myeloid metaplasia. Int J Radiat Oncol Biol Phys 1977:2:1082-9.

29. Parmentier C, Charbord P, Tibi M et al.
Splenic irradiation in myelofibrosis. Clinical findings and ferrokinetics. Int $\mathrm{J}$ Radiat Oncol Biol Phys 1977;2:1075-81.

30. Wegner H, McKeough P, Desforges J et al. Splenic irradiation in the treatment of patients with myelogenous leukaemia or myelofibrosis with myeloid metaplasia. Cancer 1986;58:1204-7.

31. Bouabdallah R Coso D, GonzagueCasabianca L, et al. Safety and efficacy of splenic irradiation in the treatment of patients with idiopathic myelofibrosis: a report on 15 patients. Leuk Res 2000; 24:491-5.

32. McFarland J, Kouzma C, Millard F et al. Palliative irradiation of the spleen. Am J Clin Oncol 2003;26:178-83.

33. Elliott MA, Tefferi A. Splenic irradiation in myelofibrosis with myeloid metaplasia: a review. Blood Rev 1999;13:163-70.

34. Down JD, Boudewijn A, van Os $\mathrm{R}$ et al. Variations in radiation and repair among different hematopoietic stem cell subset following fractionated irradiation. Blood 1995;86:122-7.

35. Van OS R, Thames HD, Konings AW et al.
Radiation dose-fractionation and doserate relationships for long term repopulating hemopoietic stem cells in a murine bone marrow transplant model. Radiat Res 1993;136:118-25

36. Joiner MC, Marples B, Lambin P et al. Low dose hypersensivity: current status and possible mechanism. Int J Radiat Oncol Biol Phys 2001;49:379-89.

37. Marples B, Wounters BG, Collis SJ et al. Low-dose hypersensivity: a consequence of ineffective cell cycle arrest of radiationdamaged G2-phase cells. Radiat Res 2004; 161:247-55.

38. Harney J, Short S, Shah N et al. Low dose hyper-radiosensivity in metastatic tumors. Int J Radiat Oncol Biol Phys 2004;59:11905.

39. Yorke E, Jackson A, Rosenzweig KE et al. Correlation of dosimetric factors and radiation pneumonitis for non-small cell lung cancer patients in a recently completed dose escalation study. Int $\mathrm{J}$ Radiat Oncol Biol Phys 2005;63:672-82. 